\title{
Cinema E interculturalidade EM “O Mestre E O DIVINO"
}

\begin{abstract}
Maria de Nazaré Cavalcante de Sousa ${ }^{1}$
RESUMO: “O Mestre e o Divino" (2013), documentário dirigido por Thiago Campos, revela formas da colonialidade do ver instituídas pelo imaginário eurocêntrico e processadas na relação conflitiva entre dois personagens: o imigrante europeu e o nativo latino-americano. O filme apresenta sutilezas que dizem muito sobre a absolutização da cultura imposta como referência de criatividade, e, ao mesmo tempo, desdiz sabiamente quando aponta a luta travada contra a imponência e a inferência na'domesticação' indígena. Aborda o processo de interculturalidade questionando a ideia de pertencimento a uma cultura. Desafia a re-pensar nas imagens cinematográficas a manutenção da invisibilidade do colonizado diante de imposição religiosa e a reprodução de imagem de 'civilidade' que permanece na América Latina. Com base na teoria da decolonialidade do ver e as relações de interculturalidades na perspectiva defendida por Catherine Walsh, neste artigo, o referido documentário é tomada como objeto de estudo para uma reflexão sobre o processo de inferiorização racial e epistêmica impresso em produções imagéticas na América Latina.
\end{abstract}

PALAVRAS-CHAVE: Imagem. Interculturalidade. América Latina. Decolonialidade. Cultura.

\section{Os olhares estrangeiro e nativo}

O filme O Mestre e o Divino, produzido pela ONG "vídeos nas aldeias" com formato de documentário, destaca-se por não abordar de forma estereotipada o indígena convertido em figura trágica, vítima histórica da dizimação que vivera no período de colonização. O filme traz Manifestação de imagens inusitadas entre dois protagonistas que nasceram em universos culturais diferentes e que convivem há anos com estas diferenças. Realizado em 85 minutos, a obra mostra vidas confrontadas e compartilhadas entre situações de diversidades culturais. Os personagens são o missionário alemão Adalbert Heide e o índio Xavante Divino Tserewahú, também contracenando, o mineiro Thiago Campos, diretor do longa metragem que participa como um personagem enunciador na Doutora em Teoria Literária, Professora da Universidade Federal do Acre. 
seqüência da história. Os três apresentam marcos definidores de abismos culturais entre si. Além disso, o roteiro aponta em sua temática para os traços de interculturalidade nas relações cotidianas e nos conflitos pessoais, como também certifica a importância de comunidades indígenas em dominarem instrumentos tecnológicos que conformem suas visualidades no sentido de propiciar novas maneiras de contar suas narrativas, com a possibilidade de re-definir histórias institucionalizadas que serviram de manutenção no imaginário cultural da etnia indígena através, principalmente, da construção de imagens materializadas.

O cenário é uma comunidade Xavante localizada no Estado de Mato Grosso do Sul. A trama inicial vigora a partir dos registros feitos em câmera super 8 por Adalbert Heide quando chega ao Brasil para trabalhar em uma missão religiosa por volta de 1950. No contraponto, a história de Divino, jovem documentarista que resolve seguir os passos do mestre na arte de construir visualidades. Convivendo desde a infância com a catequização, educação e transmissão de valores dos brancos, o cineasta indígena cria laços de afetividade e respeito pelo mestre, sem, no entanto, deixar de lutar pelo seu espaço, principalmente quando percebe a 'ciumeira' deste em aceitá-lo como um concorrente no registro da história de seu povo.

Numa abordagem perspicaz, partindo dos documentários de Heide, o enredo irá deslizando sobre a complexidade das relações humanas em suas diferenças culturais e denuncia o contundente processo de aculturação que estes missionários estavam incumbidos de realizar em terras brasileiras ao longo do século XX, além de acenar de forma inteligente para a resistência cultural. Mediada por Thiago Campos, a narrativa entremeará a amizade nutrida entre os dois personagens, como também os conflitos de gerações e a rivalidades estabelecidas entre ambos sobre a condução da história, em especial, na disputa pela protagonização e organização das imagens dos Xavantes.

O roteiro une uma proposta estética de cinema que aborda a imagem que se faz e se publica por indígenas em suas comunidades como registro dos aspectos de sua identidade cultural. Através das organizações das imagens e planos definidos para a execução deste cinema, há o desafio de re-pensar nas imagens cinematográficas a manutenção da invisibilidade do colonizado diante 
de imposição religiosa, educacional e a reprodução de 'civilidade' que permanece na América Latina, como também possibilita discutir sobre a importância de avaliar os confrontos de interculturalidade numa perspectiva dialética dentro do espaço latino-americano.

No filme chama a atenção a potencialidade das imagens e as formas que cada cineasta (Adalbert e Divino) disputam a maneira de registrar, enquadrando-as conforme preceitos sobre o lugar e referenciais de existência e cultura de cada um. Há uma disputa em torno das imagens - imagens criadas pelo padre europeu e as reveladas pelo indígena brasileiro Divino, ambas minuciosamente ponderadas pelo diretor da obra Thiago Campos. As faces dos registros propõem as fronteiras conflitivas e posturas políticas destes, um embate através de imagens que estão presentes numa relação de cumplicidade. Um traduz os modos de pensar uma realidade e um povo, mostrando a visão do 'civilizador’ carregado do imaginário eurocêntrico em relação aos povos indígenas e a floresta brasileira, o outro que busca utilizar um instrumento que tem se tornado popular com o advento da globalização, vendo nele um importante depositário das histórias de seu povo. Assim, os abismos culturais passam a ser enredados dialeticamente no interior da trama.

Os conceitos de arte e estética podem ser revistos na contemporaneidade em obra como a de Thiago Campos. É um filme que superado ponto de vista narratológico a veiculação diacrônica da hierarquia eurocêntrica. A resistência de Heide em aceitar a proposta do cinema de Divino que insiste em filmar enquadramentos de rostos, as falas de seus irmãos, ao invés, segundo o missionário, de filmar a natureza, os pássaros, árvores, rios, um olhar posicionado no estrangeiro que re-afirma a mentalidade arraigada destes na construção estética do perfil romântico do século XIX, cuja natureza é o grande protagonista da pureza, da beleza e da ética - conceitos reverenciados na clássica aristotélica além de reforçar a ideia do bom selvagem cultivado no imaginário eurocêntrico, tudo isso avança na proposta de uma visualidade que cause o estranhamento necessário à obra de arte.

A crítica do missionário aos filmes de Divino reflete as múltiplas formas de opressão presentes em imagens, sons, de um gesto na direção 
de poder que foi sendo instituídos no processo de colonização. Heide questiona o descaso de Divino pelos elementos da natureza, salientando o pouco interesse deste pelo o que considera a riqueza maior do Brasil. A atitude de Heide demonstra a visão que o outro, o colonizador valoriza em sua convivência no país e a importância dada ao nativo brasileiro na sua construção fílmica. Por esta atitude, vê-se a desvalorização do sujeito em detrimento de certos elementos da natureza. Para Didi Huberman (2010), o olhar e a escuta supõem implicações, afetações, mostrando que todo olhar e o pensamento sobre a imagem refletem o olhar que deseja ver nessa imagem. Ao inverter o olhar desejado por Heide, Divino recupera a prioridade do 'ser', da valorização identitária, numa região de referencia global cuja exuberância e exotismo da mata é sempre mostrada como protagonista.

Há uma hierarquia marcada entre sistemas visuais ocidentais e não-ocidentais implantados a partir de uma série de mecanismos tecnológicos, iconográficos, psicológicos e culturais integrados ao sistema colonial de poder e conhecimento. Filmes como O Mestre e o Divino alertam para re-pensar a oficialização da imagem eurocêntrica - que determinou uma visualidade voltada pela ideia homogênea de espaço - tornando-se urgente descolonizar essa sistematização de visualidades, já que é um produto da rede ótica, de perspectiva renascentista incutidas principalmente pelo saber acadêmico. Nesse sentido, o filme de Thiago Campos desperta para repensar a dinâmica de construções imagéticas sobre este olhar.

\section{A colonialidade do ver}

Ao cobrar que o índio registrasse a beleza natural para causar uma estética do belo e da perfeição pela idéia de natureza, Adalbert Heide revela o desejo da unificação de um imaginário sobre a região, uma forma de visualidade que tem sido divulgada e preservada em arquivos cinematográficos para serem convertidos em propaganda e definição do lugar. O pesquisador equatoriano $\mathrm{Ch}$ ristian León (2010) ao discorrer sobre a questão da colonialidade visual, afirma que há uma hierarquia marcada entre sistemas visuais ocidentais e não-ocidentais implantados a partir de uma série de mecanismos tecnológicos integrados a sistemas coloniais de poder. Por isso, há um controle subjetivamente construído sobre categorias e classificação do que pode ser estético seguindo uma concepção eurocentrada. É o Ocidente determinando o que deve ser explorado e o 
que deve ser classificatório inerente às imagens sobre suas ex-colônias. Assim, o missionário alemão, mesmo vivendo há mais de meio século entre os indígenas, mantém o ideário estético definido pelo cultuar aristotélico de arte, como forma de superioridade cultural.

As imagens presentes no processo de colonização- sejam garatujas, rabiscos e, no século XIX, as fotografias, o cinema, a televisão, século XX - auxiliaram na consolidação de uma matriz cultural determinante do imaginário sócio-cultural da América Latina. Numa proposição conceitual, ao ler uma imagem deveria indagar-se sobre a colonialidade nela inscrita, é o que alguns pensadores irão chamar de um projeto de construção da imagem do mundo, uma perspectiva que tentam recuperar o extenso período que não houve uma preocupação sistemática como a construção imagética colonial. Para instigar uma avaliação desse processo, Joaquim Barriendos (2010) irá propor que se leia imagens a partir da perspectiva decolonial, um deslocamento do pensamento epistemológico Ocidental que colonizaram os saberes e as disciplinas modernas, abrindo um pensamento outro que reinaugura uma nova forma conceber a modernidade desde uma pluralidade do ponto de vista da enunciação geopolítica. Para isso, afirma, tal prática implica re-pensar os tempos-espaços como estruturas interconectadas entre si. Segundo Barriendos, não lemos uma imagem desde o passado, a lemos através do passado e desde o presente; toda imagem se sustenta em uma forma específica e intencionada de entender e interpretar o mundo:

es necesario que el problema de la invención del Nuevo Mundo sea replanteada tomando como punto de referencia la geopolítica del conocimiento, los diferentes regímenes de visualidad de La modernidad/colonialidad, las retóricas visuales sobre el canibalismo de Indias, la función geo-epistémica de las cartografias imperiales, las economias simbólicas trasatlánticas surgidas em el siglo XVI y los diferentes regímenes heterárquicos de racialización epistêmica de La alteridad... (BARRIENDOS, 2010, p. 137).

As imagens constroem conhecimentos, articulam retóricas de poder e, sobretudo, tomam parte da formação do ser enquanto sujeitos a partir de como é visto determinado objeto ou sujeito, tanto da dimensão consciente 
como desde o inconsciente. A fotografia, o cinema e a televisão, na América Latina, foram, por longo tempo, artefatos nas mãos de grupos de poder e de grupos privilegiados pelos quais chegou-se a conhecer mais sobre a subjetividade de quem está atrás da lente que dos sujeitos observados. Para Barriendos as cartografias imperiais, imagens-arquivos e o canibalismo, definida pela perspectiva eurocentrada impuseram uma matriz discriminatória da alteridade do selvagem que se distanciava da imagem do outro que estava no centro. Dai tal padrão de poder que não reconhece o outro, através da visualidade, ser denominado de colonialidade do ver.

Com o advento recente da internet e com o barateamento de instrumentos de projeção, o monopólio, de certa forma, é desfeito, e uma visão alternativa de arte passa a ser mais democratizada e rediscutida, produzida ou reproduzida. Surge uma forma de expressão da arte através de saberes alternativos, embora pairem dúvidas e críticas sobre essa profusão de visualidades. Nesse momento, pode-se considerar uma possível ruptura epistemológica com a estética e a cultura visual hegemônica, dando lugar a incertezas e divagações que podem desconstruir bases solidificadas de imagens divulgadas academicamente de convenções de visualidades estabelecidas pela colonialidade do ver. Com isso, é possível observar, na rede mundial de comunicação virtual, uma proposta de quebra de barreiras que, até então, parecia intransponível. Os projetos ligados à produção de cinemas indígenas e outros projetos alternativos de cinema e vídeos se apresenta como um promissor e forte desafio contra a hegemonia visual.

Walter Mignolo (2010) ao falar sobre a existência de colonialidade na América Latina, aponta para a escassez de um estudo mais apurado sobre a imposição ideológica mantida por imagens ao longo desse processo; assim, irá defender que haja maior interesse pelos estudos visuais latino-americano, pois os considera muito incipientes. Para o pesquisador é necessário caminhar para uma crítica decolonial que questione o olhar narcisista histórico da cultura européia e a própria razão moderna, ou seja, defender um deslocamento da epistemologia ocidental na perspectiva que reinaugure uma nova forma de pensar desde uma pluralidade do ponto de vista da enunciação geo-histórica. A colonialidade visual é exponencial a um imaginário e na veiculação da memória de 
imagens produzidas e reproduzidas mecanicamente. Ainda hoje, a manipulação de informações e de imagens no sistema global é explícita.

Para o pesquisador Christian León (2010) há uma tele-colonialidade que trabalha sob o controle geo-político da alteridade a nível global, administrando imagens à distancia que estão intimamente relacionadas com a cartografia geopolítica da modernidade-colonialidade:

Los debates sobre cultura visual que se dieron em El primer mundo partieron de um abandono Del enfoque histórico em um paradigma antropológico integrador que analice La imagen, las tecnologias, las instituciones y las prácticas cotidianas Del ver em tanto nuevas realidades Del capitalismo globalizado.Los debates sobre cultura visual pensados desde América Latina están llamados a reintroducir La historia em El pensamiento de La imagen y a plantear La discontunuidad geográfica que asedia al campo de La visualidad (LEON, 2010, p. 37).

A colonialidade do ver a partir de uma análise do histórico constitutivo de imposição de saber, poder e do ser mostra consistência em uma série de derivações e reformulações hierárquicas, desde o padrão de poder os quais interconectam a partir do século XV ao XXI. Barriendos cita o artista equatoriano Tomas Ochoa que avança no ideal de articular nova etnografia crítica dos regimes visuais do mundo ocidental; seu trabalho disserta sobre a re-contextualização de documentos e rompe imagens de arquivos relacionadas com a expansão da Europa para o 'novo mundo'. Para esta desconstrução o artista utiliza seus vídeos e os posiciona em diversas formas de serem observados, sem disciplinar um olhar surgido das mãos da modernidade. A pragmática de Ochoa, segundo Barriendos, é para causar impacto contra a suposta imparcialidade da imagem visual etnográfica, apresentando uma perspectiva decolonial desta imagem.

Em O Mestre e o Divino se percebe o intuito de romper com esta manipulação de imagens de colonialidade. Os vídeos que são produzidos por Divino são resultados de um sujeito em busca de sua identidade, enfrentando sua formação religiosa e acadêmica apreendida na cultura do outro. Rompe com esse processo de negação de sua origem a que foi sujeitado, revela-se um ser fortemente ligado às suas raízes, consegue distinguir sobre os dois mundos focados, podendo intervir de maneira crítica sobre sua memória, utilizando para 
isso o recurso visual. Assim, em cenas do filme, mostrará em primeiro plano seus irmãos de etnia, o falar dos mais velhos da tribo, priorizando a divulgação das manifestações culturais através da manifestação direta de seu povo, e torna secundário, senão exclui de seu projeto cinematográfico, a descrição do exotismo da natureza tão exaltada pelo estrangeiro, representado em seu mestre.

As imagens mostradas delineiam uma seqüência dramática, uma estruturação de roteiro propondo outra lógica, um tempo e um conteúdo de interesse comum ao universo indígena. Thiago aproveita para filmar Divino dirigindo e ensinando outros parceiros a produzir vídeos. Ao destacar em seus vídeos a transmissão da memória a partir dos mais velhos e colocando os mais novos para aprender a editar e gravar tais narrativas, o protagonista trabalha com a expressão da subjetividade humana em detrimento da natureza. Expõe um diálogo do protagonista com seu espaço interatuando e registrando a essência humana. É a expressão da arte que se converte nesse momento em vivência. Em conseqüência, a arte passa a ser a expressão da vida desses homens e mulheres. $\mathrm{O}$ documentário propõe um novo acordo visual, um diálogo visual inter-epistêmico com os regimes visuais canonizados.

Marcando a hierarquia que aborda o sistema visual definido pelo Ocidente, os filmes, em super oito, de Heide produzem e mantêm o exotismo do mundo tropical, o bucolismo da natureza e a exaltação do selvagem retratados com grandeza épica, destacando-se o protagonismo do cineasta alemão nas ações. Os registros funcionam como a aventura do missionário Heide entre os índios xavantes no interior do Brasil, imagens de um país da América Latina para ser mostrado na Alemanha. Grande parte deste acervo já se encontra lá, como constata o diretor do filme, que narra em voz over sua viagem para uma congregação religiosa na Alemanha que detém o direito do material produzido sobre os índios xavantes realizado pelo mestre ao longo destes 60 anos. Um aprisionamento em museus europeus de uma leitura racializada e hierarquizada dos indígenas xavantes, os povos da América colonizada.

Outro momento de pontual presença de colonialidade do ver é mostrado nos filmes selecionados por Heide para divertir os indígenas. Confirmando o seu papel de colonizador, o missionário projeta um estilo de 
cinema norte-americano, um faroeste, cinema de grande representação do processo de invasão branca em terras indígenas nos Estados Unidos. Imprime nessa atitude, com pretexto de diversão, a marca do extermínio indígena mostrado no cinema do século XX, buscando, com isso, legitimar a prática do processo de invasão na América Latina, Além de, sobretudo, submeter a comunidade à ideologia do branco como herói e do índio como um subalterno.

Por diversas vezes esse faroeste é exibido por Heide na comunidade. A história dar conta da extremada dedicação de um índio apache ao branco herói e amigo. $\mathrm{Na}$ conversa com Thiago, o velho missionário compara o pupilo Divino ao índio do filme que na trama é assassinado pelo bandido no momento em que se antepõe a uma arma de fogo que mirava e foi acionada contra o suposto herói branco, entregando a própria vida para salvar o protagonista. As imagens selecionadas no documentário encaminham à reflexão sobre as formas que se articulam retóricas de poder, da necessidade da subalternização do mestiço para sustentação e formação de sujeito-objeto, gerando neste sentido um regime visual canonizado pela elite cultural.

\section{A questão da Interculturalidade}

Mas não apenas pelas marcas de colonialidade $O$ Mestre e o Divino se expressa. As abordagens fílmicas também possibilitam visualidades no campo das relações de culturalidade. Thiago Campos não somente levanta a questão da imposição do colonizador, mas cerca o público com imagens que questionam a lógica cultural do eurocentrismo e ao mesmo tempo coloca em jogo a dinâmica das trocas de conhecimentos, de posição de mundo e, sobretudo, a diferença étnica e religiosa trazidas pelo europeu. Dá-se nessas imagens o que pode ser considerada uma relação de confronto entre culturas apontando para uma dinâmica de interculturalidade do ponto de vista crítico, como defende Catherine Walsh (2009):

Dentro de um debate intercultural estão em jogo ações que procuram naturalizar e harmonizar as relações culturais a partir de uma matriz de hegemonia e dominação, a cultura do centro, uma língua dominante, uma estrutura política como referência etc. No entanto, encontra-se outra perspectiva nesse diálogo intercultural, o de denunciar o caráter político, social e confliti- 
vo destas relações e que concebem a cultura como um campo de batalha ideológico e de luta pelo controle da produção de verdades e pela hegemonia cultural e política (WALSH, 2009, p. 08).

Walsh centraliza sua análise sobre a importância do reconhecimento das raízes milenares em confronto com toda forma de dominação e colonialismo, enfatizando a valorização da pachamama, como parte vital da existência, e à necessidade urgente de conviver para o 'bem viver', buscando formas de uma convivência harmoniosa que o modo de organização da república não contempla. Nesse sentido, a pesquisadora evoca retomar as leis, o reconhecimento das formas de vidas indígenas e dos afro-descentes.

O que se percebe nesse sentido é que, na América Latina, um continente fortemente impregnado pela cultura colonialista, as práticas interculturais acontecidas nas relações sociais têm sido um desafio para instituições, organizações e os movimentos sociais. São negociações travadas e que acontecem nas lutas por espaço no trabalho, na escola no lazer, na arte, nos costumes, buscando definir-se nos espaços escolhidos para viver e interatuar. Daí nesse processo de identidade co-existem diferentes estilos, diferentes saberes, pertencimentos e subjetividades. As formas como re-criam dentro de uma obra midiática essas trocas, dependendo da abordagem, da concepção, dos princípios norteadores que se deseja extrair, vão acontecer dinâmicas de culturalidades funcional ou crítica no contexto latino-americano.

Para Fidel Tubino (2012), o interculturalismo funcional defende a necessidade do diálogo e o reconhecimento intercultural, mas não avalia neste contexto o estado de pobreza crônica da grande maioria da população e estado de subalternização em que se encontram as culturas. No interculturalismo funcional, ocorre um apagamento do discurso sobre a condição de miséria pelo discurso sobre a cultura, ignorando a importância que tem ambos para se compreender as relações interculturais. Situações como a injusta, a distribuição de renda, a desigualdade econômica, as relações de poder e os desníveis culturais internos concernentes aos comportamentos e concepções dos estratos subalternos e periféricos da mesma sociedade. 
Quanto ao interculturalismo crítico, Tubino acredita que a intenção seja diferente. Enquanto que o funcional promove o diálogo sem tocar as causas da assimetria cultural, o crítico suprime as assimetrias existentes. Colocando de forma mais exata, propõe que o interculturalismo crítico exige que o diálogo entre as culturas seja a porta de entrada para discutir os fatores econômicos, políticos e sociais, fatores essenciais para haver trocas francas entre as culturas da humanidade: 'para hacer real el diálogo hay que empezar por visibilizar las causas del no-diálogo' (TUBINO, 2012, p. 06).

Walsh, que prefere utilizar o termo interculturalidade, crê que a interculturalidade crítica de fala Tubino, negocia formas de convivência, como também, questiona a lógica do capitalismo e aponta para outra sociedade, propõe mudanças radicais na estruturas institucionais e relações sociais, pois essa linha se trata de um projeto político, ético e epistêmico que envolve principalmente os movimentos indígenas, aqui se referindo aos andinos que surgiram nos anos de 1980: 'No existe, es algo por construir, costuma dizer a pesquisadora.

Para Catherine Wash, a questão da interculturalidade passa pelo viés epistemológico e direciona a discussão sobre a racialização na modernidade-colonialidade que insiste em alimentar o pensamento kantiano da existência humano e o menos humano, quando forjaram a ideia de que os índios e negros são não racionais ou com menos capacidade de pensamento. Dai defender uma postura mais definida quanto às práticas de trocas culturais entre povos e fronteiras, avaliando uma atuação crítica em relação a essas trocas.

Analisando o papel do discurso visual que apresenta traços de interculturalidade direcionados para as relações fronteiriças e ações afirmativas quanto à diversidade étnicas, Andrea França (2010) chama atenção para o papel significativo do cinema na articulação e na perpetuação do que poderia ser chamado de mitologias globais que intensificam os discursos ideológicos sobre o mundo e sua relação com a humanidade. Ao relacionar o cinema e sua importância no processo de globalização, Bill Nichols (1997) insiste que este deve ser realocado como meio dentro do contexto maior das indústrias globais. Isso significa tratar o cinema - como historicamente tem sido o caso - não isolado de outras mídias, mas como parte de um continuum maior. Para Nichols, o cinema inventa espaços de solidariedade transnacionais, espaços que ensejam uma espé- 
cie de adesão silenciosa. O cinema tem a potência de acentuar a singularidade de uma comunidade de diferentes.

Hudson Moura (2010) observa que a interculturalidade no cinema tenta traduzir em imagens a experiência de viver entre duas ou mais culturas e sociedades diferentes, que concebem novas formas de pensar e de conhecimento. É um cinema compartilhado por pessoas que sofreram o deslocamento e que viveram modos híbridos e para quem a representação do cinema convencional não traduz a complexidade do deslocamento. Esses cineastas, considerado por Moura como emergentes, distanciam-se dos clichês habituais sustentados pelos cinemas convencionais em relação ao outro.

Em O Mestre e o Divino, a questão da racialidade é pertinente, todavia a linha condutora da trama é o confronto, resistência e cumplicidades em relação às fronteiras culturais entre colonizador e colonizado. Inúmeras situações conflitivas são deflagradas através do diálogo entre os dois, algumas vezes mediadas em voz over pelo diretor do filme, que tentar traduzir nas imagens a experiência da convivência entre duas culturas e as possibilidades de reconhecimento de ambos nas trocas de experiências. Nesse instante é inserido o olhar do mestiço brasileiro e sua relação com as duas culturas em jogo. O embate maior está nas trocas estabelecidas entre os dois mundos postos, em foco a visão eurocêntrica da América Latina e o pensamento sobre o sujeito latino-americano, representado no indígena, e a construção da subjetividade humana inserida nos vídeos criados por Divino, tudo conduzido de uma forma reflexiva e não purista sobre as relações culturais.

Juan Escobar (2006) procura distinguir a visão extremista sobre pureza cultural. Afirma que ao construir a imagem do indígena e suas relações fronteiriças deve haver cuidado porque as culturas absorvem as influências externas e propriamente no interior das culturas se produzem transformações e se convertem em significados próprios. A maioria dos documentários sobre a questão indígena, para Silva Escobar, traz discursos encráticos à luz do poder:

Un número considerable de los documentales realizados en nuestro país tratan el tema indígena. En tanto algunos de ellos tienen como objetivo representar esas culturas o algún aspecto de ellas, no pocos se plantean como documentos de denuncia 
y reivindicación de las causas indígenas. ¿En qué medida estos textos logran cuestionar los estereotipos, romper los esquemas, transgredir los modelos de representación? (SLVA ESCOBAR, 2006).

Divino, no filme, é um indígena que não representa a figura trágica geralmente construída em torno das etnias latino-americanas; ele representa a resistência e a luta contra a institucionalização da colonialidade. O xavante. consciente de seu papel na comunidade, estabelece um diálogo com o alemão Heide sobre os diferentes mundos que os dois defendem. Vê-se uma relação de subalternidade em alguns momentos, e, ao mesmo tempo, de desafio sobre autoridade e visões de mundo. Nas provocações feitas constantemente ao mestre, Divino subjetivamente reconhece ser um sujeito colonizado, mas ao estabelecer o diálogo, os questionamentos, os confrontos sobre as práticas culturais exercidas pelo mestre tornam por fortalecer o pensamento de interculturalidade como um possível diálogo universal entre iguais. Ao público é dada a possibilidade de divagar nas construções subjetivas tão imprecisas sobre a posição de cada personagem.

Talvez o que define uma posição mais precisa pode está na ideia de circularidade dos conflitos que propõe o filme. Travando um diálogo com novas formas de inserção de imagens na busca de recuperação do passado, não em sua pureza, mas como pensamento fronteiriço crítico, além de levantar uma proposição de que vários mundos, várias culturas caibam dentro de um mundo, que os sujeitos podem sentir-se sujeitos pertencentes a uma comunidade compartilhando as igualdades e desigualdades, sem deixar de ter em vista o rompimento da matriz colonial.

\section{Cinema AND inTERCUlturality in MASTER AND Divino}

ABSTRACT: Master and Divino (2013), is a documentary directed by Thiago Campos: it reveals forms of colonial imagery imposed by Eurocentrism, epitomised by the conflictual relationship between two of the characters: a European immigrant and the native Latin American. The script explores aesthetics proposals that approach the imagery that is fabricated around people of diverse cultures. Some details reveal a lot about the absolutisation of culture imposed as a reference to creativity and, at the same time, negate all this when pointing to the struggle against the grandeur and meticulousness of the "domestication" of the natives. The movie also addresses the process of interculturality 
by questioning the idea of belonging to a determinate culture, and challenges the audience into reconsidering, in cinematographic images, the maintenance of the invisibility of the colonised, in the face of the religious impositions and the reproduction of images of "civilisation" that are persistent in Latin America. Based on the theory of decoloniality of gaze and on the relations of interculturality in a critical perspective as proposed by Catherine Walsh, this work takes the presented movie as an object of reflection on the process of racial and epistemic inferiorisation, which in turn marks the visual creative production of this continent.

KEY WORDS: Image. Interculturality. Latin America. Decoloniality. Culture.

\section{Referências}

DIDI-HUBERMAN, G. O que vemos, o que nos olha. Trad. Paulo Neves. São Paulo: Editora 34Ltda, 2010.

GONÇALVES, G. S. Território imaginado: imagens da Amazônia no cinema. 2009. Dissertação - Universidade Federal do Amazonas, Manaus, 2009.

LEAL FILHO, L. Atrás das câmeras. Relações entre cultura, estado e televisão. São Paulo: Summus, 1988.

LOPES, D.; FRANÇA, A. Cinema, globalização e Interculturalidade. Chapecó,SC: Argos, 2010.

LOPES, M. I. V. (Org.). Telenovela - Internacionalização e Interculturalidade. São Paulo: Edições Loyola, 2004.

LUDMER, J. Aqui América Latina: Uma especulación. 1. ed. Buenos Aires: Eterna Cadência editora, 2010.

MARTIN, M. A linguagem cinematográfica. Tradução de: Paulo Neves, São Paulo: Brasiliense, 1990.

MARTÍN-BARBERO, J. Comunicación y cultura: unas relaciones complejas. In: Revista Telos, Madri, 1989.

MOURA, H. O cinema intercultural na era da globalização. In: Cinema, globalização e interculturalidade,Andréa França e Denilson Lopes(org.). Chapecó, SC:Argos, 2010

MOURÃO, M. D; LABAKI, A. (Orgs.). O cinema do real. São Paulo: Conac Naify, 2008.

MURATORIO, B. Imágenes e imagineros. In: Representaciones de los indígenas ecuatorianos, siglo XIX y XX, FLACSO, Ecuador, Quito, 1994. 
NICHOLS, B. La representación de la realidad - cuestiones y conceptos sobre el documental. Barcelona: Ediciones Paidós Ibérica S.A., 1997.

SILVA, F. O. O cinema indigenizado de Divino Tserewahú. Dissertação (Mestrado) - Universidade Federal de São Paulo, Escola de Filosofia, Letras e Ciências Humanas, Guarulhos, 2013.

SILVA ESCOBAR, J. P. Discursos de Frontera: La otredad y la mismidad en tres documentales. Rev. austral cienc. soc., 2006, no.10, p.121-136. ISSN 0718-1795. TUBINO, F. Del interculturalismo funcional al interculturalismo crítico. Disponível em: www.fongdcam.org. Acesso em: 05 out. 2012.

WALSH, C. Interculturalidad, descolonización del estado y del conocimento. Buenos Aires: Del Signo, 2006.

WALSH, C. Temas de Interculturalidad Crítica. Chiapas, México: Edición impresa para uso privado SCLC, 2009.

XAVIER ALBÓ, S. J. Cultura, interculturalidade, inculturação. Tradução de: Yvonne Mantoanelli. São Paulo: Edições Loyola, 2005.

Data de recebimento: 15/11/2014

Data de aceite: 10/12/2014 